\title{
Transcultural Flow of Demure Aesthetics: Examining Cultural Globalisation through Gothic \& Lolita Fashion
}

\author{
Masafumi Monden \\ University of Technology, Sydney
}

\begin{abstract}
The process of cultural globalisation does not always imply cultural homogenisation. Rather, it can be seen as a process of cultural 'glocalisation' and hybridisation where cultures continuously interact with and interpret each other to engender a hybrid cultural form. As Arjun Appadurai (1993) contends, neither centrality nor peripherality of culture exists in the context of cultural globalisation. Rather, transnational cultural forms are likely to circulate in multiple directions.

This is particularly evident when examining Gothic \& Lolita - a Japanese fashion trend which has emerged since the late 1990s. Applying Jan Nederveen Pieterse's theory of 'globalisation as hybridisation' (2004), and Roland Robertson's concept of 'glocalisation' (1995), this article attempts to explore how this fashion trend manifests the process of cultural 'glocalisation', hybridisation, and interaction through the localisation of Western Goth subculture and especially, historical European dress styles in Japan. In addition, it explores how the fashion signifies the idea of 'reverse' flow of culture through an ethnographic observation of an English-speaking online community devoted to the trend. The analysis of the online community also seeks to establish the idea that this transnational cultural flow serves as an alternative to the local culture.
\end{abstract}

\section{Keywords}

Cultural Globalisation, Japanese Fashion, Goth Subculture, Cross-cultural appropriation, Aesthetics of Cute

\section{Introduction}

A young woman is waiting for the traffic light to turn green on a busy street. She is dressed in a white, long-sleeved, frilly blouse, a black pinafore dress trimmed with white lace, black knee length socks, and a white pair of 'Mary Jane' shoes. A lacy, white headdress adorns her delicately curled light brown hair, and her black parasol trimmed 
.

with black ribbons protects her from the attack of the ultraviolet rays, which threaten her pallid complexion. Although the girl appears to have slipped out of Lewis Carroll's famous Alice's Adventures in Wonderland, no one around her seems to pay particular attention to her appearance. This is Harajuku, an area known for its striking fashion in Japan.

On the other side of the globe sits a young woman with dyed-black hair, dressed in a punk-styled t-shirt, a red checked high waisted mini skirt with triple frilled hem and white lace, black and white knee-high striped socks, and Dr Martens boots. Her computer monitor displays a site with a picture of a girl in Japanese manga style, wearing a small hat, ivory-coloured puff-sleeved blouse, and a black, corseted high waisted skirt. She is browsing an online community; perhaps in hope of finding people who appreciate the same taste in fashion as her. This is Finland. These two women, though separated physically by a great distance, have something in common -they follow the same set of fashion aesthetics, which allows them to dress in lace and frills without seeking the objectifying male gaze. They also read the same Japanese manga, and appreciate the gothic aesthetic of Tim Burton's films. This article will discuss these connections in order to examine the processes of transcultural flow, which are likely to circulate in multiple directions.

This article pays particular attention to the theory of globalisation as hybridisation' put forward by sociology scholar Jan Nederveen Pieterse. His theory argues that cultural globalisation does not simply involve a dominant culture infiltrating weaker others, but is rather a series of processes that involve cultural hybridisation. Similarly, sociologist Roland Robertson articulates the theory of 'glocalisation', stating that globalisation of culture does not necessarily lead to the homogenisation of (and by implication destruction of) local cultures. This is because the processes of global homogenisation and heterogenisation are 'mutually implicative' ${ }^{\text {'1 }}$ because local is defined by global, and 'when one considers them closely, they each have a local, diversifying aspect.' Robertson's argument rejects the notion that globalisation is merely cultural homogenisation, and indicates instead practices of cultural interaction, interface and appropriation, which take place when a cultural form is accepted and then indigenised in another culture. Social-cultural anthropologist Arjun Appadurai reinforces this idea, arguing that 'at least as rapidly as forces from various metropolises are brought into new societies they tend to become indigenized in one or another way. ${ }^{3}$ In this sense, he contends that when a culture becomes transnational, the process of localisation is likely to be involved. This process makes the transnational culture become more complex than a uniform, global culture.

Robertson, ‘Glocalization: Time-Space and Homogeneity-Heterogeneity', p. 27. Ibid., p. 34.

Appadurai, 'Disjuncture and Difference in the Global Cultural Economy', p. 274. 
Appadurai further argues that ' $[t]$ he new global cultural economy has to be seen as a complex, overlapping, disjunctive order, which cannot any longer be understood in terms of existing center-periphery models (even those which might account for multiple centers and peripheries).' Similarly, sociologist Zygmunt Bauman argues that although only privileged and wealthy individuals can conceivably celebrate globalisation, the concept represents 'the determinate, unruly and self-propelled character of world affairs: the absence of a centre, of a controlling desk, of a board of directors, a managerial office. 5 The absence of a centre of cultural globalisation, along with disjuncture and fluidity in the flow of culture, suggests the potential for countercurrents, or 'reverse' flows of culture, as cultural forms seem to circulate in multiple ways. Consequently, this idea refuses the idea of cultural imperialism, which, as cultural sociology scholar John Tomlinson puts it, 'gathers in a number of fairly discrete discourses of domination: of America over Europe, of the "West over the rest" of the world, of the core over the periphery, of the modern world over the fast-disappearing traditional one, of capitalism over more or less everything and everyone.' 6 This denies the centrality of a 'dominant' culture, which in turn suggests the potential of various cultures to in-and-outflow in multiple directions. Thus, these authors indicate the importance of observing the relationship between transnational and local cultures. Indeed, cultural globalisation is likely to involve cultural interaction and appropriation, and is operated in multiple directions.

This idea is particularly important when Western cultural forms such as fashion become transculturally appreciated in the non-West. For instance, it is too narrow to describe a Japanese street fashion as homogenised on the basis of its acceptance of Western dress style as its inspiration, since localisation and interaction with local cultural elements such as aesthetics, preferences or sociality are likely to be reflected in Japanese fashion. By focusing on the Japanese fashion trend Gothic \& Lolita, or GothLoli as it is known in Japan, I aim to amplify the idea that cultural globalisation is much more complex than cultural homogenisation, and that non-Western cultural formations can also be significant in the context of its growth and establishment. In particular, I apply a communication and cultural studies perspective in order to focus on how this fashion trend is perceived outside Japan.

The first section focuses on GothLoli in the context of cultural globalisation. It explains how this fashion trend is a manifestation of the process of cultural hybridisation, interaction through the localisation of Western Goth subculture, and especially, historic European fashion styles. The latter section develops this idea further by conducting a textual analysis of EGL the Gothic \& Lolita Fashion Community, an English-speaking

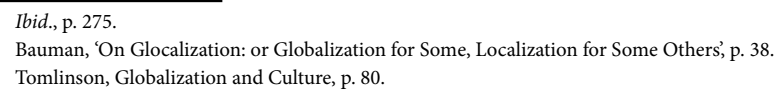


cyberspace community for GothLoli lovers. In particular, by examining the experience and opinion of those who dress in this fashion outside Japan, this section seeks to establish the idea that this transnational cultural flow serves as an alternative to the local culture rather than threatening or infiltrating it.

The example of GothLoli is well suited to this topic since this fashion trend has undoubtedly emerged from European and Japanese cultural interactions and hybridisations. Moreover, it is seemingly accepted and understood in various cultures, including Europe and the United States, as an alternative to existing cultural forms. Gothic \& Lolita has been interpreted differently in different societies, by individuals from different historical, social, and aesthetical backgrounds, denying its singularity, and challenging notions of cultural imperialism. ${ }^{7}$

\section{Gothic \& Lolita goes to the World: Globalisation and Hybridisation of GothLoli}

Gothic \& Lolita, or GothLoli is a part of a fashion trend called Lolita that emerged in Japan in the mid to late 1990s. According to writer Kyshah Hell, this trend is one where young people dress in 'amazingly elaborate Gothic looking baby doll costumes...French Maid meets Alice in Wonderland style and has expanded gradually to encompass many nuances in a Victorian Gothic look. ${ }^{8}$ Similarly, Avant Gauche, a website dedicated to Gothic \& Lolita, defines the fashion as a dress style which consists of 'cute voluminous frilly and lacey [sic] knee length dresses, frill top socks and Mary Janes. ${ }^{9}$ Luv Ishikawa in Guide to Gothic \& Lolita Culture, argues that it is a gothic subculture distinctively different from the British Goths who emerged in Japan in the mid to late 1980s, and from the mid 1990s the trend was reinvigorated with mainstream breakthroughs of Visual Rock. ${ }^{10}$ According to Japanese studies scholar Carolyn S. Stevens, Visual Rock is a form of Japanese pop rock music that makes a 'strong visual impact through hair, makeup and costume ${ }^{11}$. Although it is largely unproven, some believe Gothic \& Lolita to have been first practiced by the fans of Visual Rock singers to impersonate their favourite stars. This is indicated by the fact that one of the best known icons of this fashion trend and the owner of GothLoli clothing brand Moi-même-Moitié, is Mana the former guitarist of a Visual Rock band Malice Mizer. Although there is no clear definition of GothLoli,

\footnotetext{
$7 \quad$ This essay uses Japanese popular culture in order to observe, and in part argue that non-Western culture can be significant to Western culture too. However, this is not to assume that the West signifies the world as a whole or Japan signifies the non-West as a whole. Rather, as historian Ivan Morris states in The World of the Shining Prince (1979), Japan has actively borrowed cultural and political forms from foreign countries, most notably China and Korea in the seventh and eighth centuries. Thus, Japanese culture itself is a result of a long fusion of Asian cultures, which affirms the argument of Nederveen Pieterse that almost all cultures are likely to be cultural mélanges.

8 Hell 'Elegant Gothic Lolita'.

Avant Gauche [http://www.avantgauche.co.uk].

Ishikawa, 'Guide to Gothic \& Lolita Culture’, pp. 88-89.

1 Stevens, Japanese Popular Music, p. 56.
} 
it functions as a blanket name for varied Lolita fashions including Gothic/Black Lolita (black and white), Sweet Lolita (pastel coloured), Classical Lolita ('maiden' style with slightly less lacy and less elaborate clothes) and Gothic Aristocrat (dark but lacy and elaborate 'Count' style for both men and women). ${ }^{12}$ This fashion style was somewhat minor until Shimotsuma Monogatari (aka Kamikaze Girls), a film adaptation of the best-selling novel by the cult novelist of Japanese 'maiden' subculture Takemoto Novala, was released in 2004 and became a box-office hit in Japan and a cult film in the West. Magazine editor Suzuki Mariko suggests that GothLoli style might be modelled upon children's dresses. This fashion style, she argues, attracted girls and young women who were unhappy with mainstream fashion styles. According to Suzuki, at the beginning of the twenty-first century mainstream fashion styles for young women in Japan lacked frills and lace, and not only those who appreciated gothic subcultural elements, but also those females who wished to dress in frilly and lacy clothes embraced GothLoli. ${ }^{13}$ Their sweet and elegant aesthetics as well as their appreciation of highly 'romanticised' lives of European nobility and upper class girls in the eighteenth and nineteenth centuries (Marie Antoinette of France and Alice in Alice's Adventures in Wonderland are apparent favourites), combined with the fashion style's total lack of functionality, often persuade them to appreciate and adopt (externally) demure mannerisms.

\section{Gothic \& Lolita and Cuteness: Japanese Aesthetic}

It is easy to dismiss this fashion trend as mere mimicry of Western subculture, and hence describe it as a form of Western cultural homogenisation as both concepts of 'Gothic' and 'Lolita' are derived from the West, and it obviously reflects the influence of dress styles in eighteenth and nineteenth century Europe. However, if we consider and observe this trend more closely, its hybridised qualities become clear. One of the most prominent aspects of GothLoli as a culturally hybridised form is the interaction between Western gothic/classic fashion and the Japanese aesthetical concept of kawaii (cute). The application of the Japanese word kawaii is immensely diverse. Film studies scholar Yomota Inuhiko, for instance, argues that the word kawaii can be applied in order to describe, for example, an elderly man or a hot spring, which in other languages, he argues, would sound strange if grammatically correct. ${ }^{14}$ This illustrates the diverse nature of the word, whose definition is almost impossible to grasp. Although Yomota declines to affirm the idea that this kawaii aesthetic originates from Japanese culture, he notes that Japanese aesthetical admiration of anything young, small, fragile and

\footnotetext{
12 I use Gothic Lolita as a blanket name to describe various Lolita styles. Although it might not be entirely appropriate, this provides clarity to my points. However, diversity in the fashion trend needs to be acknowledged.

13 Suzuki, 'Gothic \& Lolita wa kansai kara umareta', p. 119.

14 Yomota, Kawaii Ron, p. 42.
} 
.n.m.n. of

cute, which he perceives as reminiscent of the contemporary kawaii aesthetics, can be traced back to the Heian period ${ }^{15}$. In general, kawaii refers to something childish/ girlish and sweet. According to sociologist Merry White, the concept of cuteness is not 'restricted to children in Japan, though it means childlike and sweet, happy and upbeat-and vulnerable' and Japanese cute style is defined as 'bright for boys, lacy for girls. ${ }^{16}$ According to freelance researcher Sharon Kinsella:

Kawaii meaning 'cute' in English essentially means childlike, and by association: adorable, innocent, simple, gentle, and vulnerable. Cute style saturated design and the mass media whilst they were expanding rapidly in Japan between the mid seventies and the mid eighties. Cute style reached its height of saccharine intensity in the early 1980s...In the mid-nineties Japanese cute returned as the more kitsch and knowing 'super- cute' (chou-kawaii). ${ }^{17}$

The aesthetical concept of cuteness is no doubt part of GothLoli, and the extensive use of lace and doll-like knee-length dresses corresponds with the concept.

\section{Western Goths vs. Japanese Gothic \& Lolita}

Compared to GothLoli, Western Goths are generally defined by their embrace of darkness and gloominess. The undertone of dark, gloomy aesthetics are also prominent in GothLoli, as many of its fashions feature symbols of bats, coffins, skulls, crosses and blackness. However, as the name Gothic \& Lolita itself indicates, it also emphasises sweetness, girlishness, and elaborateness. GothLoli is not only considerably distinctive from the Western Gothic in terms of style, but also conceptually. There is a sense that Western Gothic often symbolises rejection of and rebellion against mainstream culture. According to rhetorical and cultural studies scholar Joshua Gunn, Western Goths often see themselves as darker counterparts to mainstream culture, as they:

[C]hoose to embrace the gloomier aspects of life that (they perceive) mainstream society seeks to suppress (death, melancholy, depression, the nontranscendent sublime of confronting the realities of postmodernity). ${ }^{18}$

As a consequence, those who self-identify as Goths often oppose the media's representation, and its inclusion of such mainstream gothic cultural icons as Marilyn Manson. ${ }^{19}$ Sociology scholar Amy C. Wilkins, in her study of American Goth women,

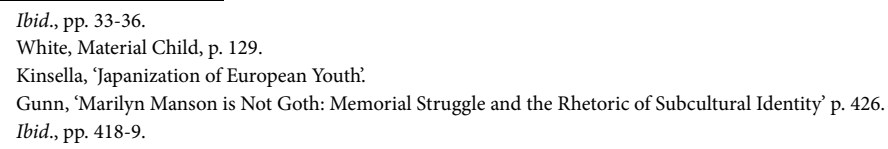


indicates that they often attempt to reject/oppose mainstream portrayals of passive femininity through celebrations of active sexuality. ${ }^{20}$ Sociologist Paul Hodkinson notes that the cultural environment of Western Goth subculture is a suitable environment where women challenge the existing, mainstream media's portrayal of passive femininity because the distinction between male and female is blurred by subcultural style. ${ }^{21}$ From these studies we can draw the idea that Western Goths often function as models to oppose, reject and rebel against existing fetters imposed by mainstream culture and society, perhaps especially those to do with gender.

The concept of 'Lolita' is perceived quite differently in the West than in Japan. As media scholar Debra Merskin states, it is named after the preadolescent heroine in the novel Lolita by Vladimir Nabokov (1958), and is often used to describe young girls dressed and posed in a highly sexualised way, or middle-aged males' paedophilic attachment to such girls. ${ }^{22}$ Merskin expresses her own concern over the current trend in Western media (especially in advertisements) of portraying young girls with highly sexualised looks, as well as the trend for more mature-aged women to dress and look like baby-dolls. She argues that this 'Lolita' look is indeed a multimedia phenomenon. Merskin cites author Judy Steed who argues that this trend is likely to fuel the fantasies of paedophiles who find that their predilections are 'reinforced by mainstream culture, movies and rock videos that glorify violent males who dominate younger, weaker sex objects.' ${ }^{23}$ In this sense, she claims that the concept of 'Lolita' operates exclusively for an objectifying male gaze. As a consequence, 'Lolita', or women dressing to achieve 'babydoll' looks, represents the objectification and sexualisation of women in the mainstream media. This indicates the limitation of media representation of women in the West. Media and communication scholars Karen Ross and Virginia Nightingale, for example, cite media studies scholar Marian Meyers who argues that women are often represented by the media as either 'Madonna' or 'Whore', for 'women are either innocent victims of male lust and violence or guilty of incitement by their own behaviour and conduct.' ${ }^{24}$ This dichotomy is also mentioned by Merskin who argues that the concept of (American) 'Lolita' in fashion advertising, and in other media, is to 'appear vampish, but be virginal', which means, she argues, to appear sexually provocative (Whore), but remain nonthreatening to men (Madonna). ${ }^{25}$ In contrast to their representation of females, the media tend to emphasise male aggressiveness. Music journalist Stuart Berman, for instance, argues that American music reflects wider gender stereotypes in that male singers are assumed to be aggressive while female singers are assumed to be coquettish

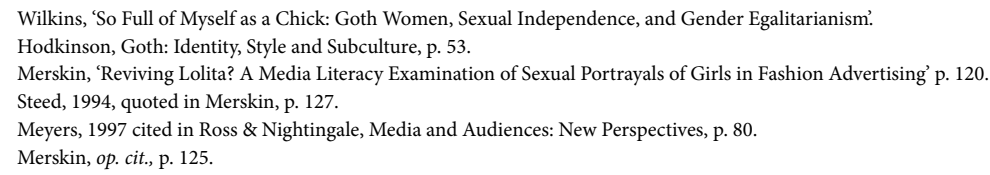


.

and fragile. ${ }^{26}$ Thus, it can be seen that in mainstream Western media, this limited 'Madonna-Whore' representation of women and girls as well as the representation of masculinity as aggressive still strongly persists. This limited representation of gender in mainstream media seems to impose a negative conception of femininity and in turn the qualities such as elegance and sweetness that are associated with it.

In contrast to these points, subcultural aspects of GothLoli have been fading as Japanese youth who dress in GothLoli increasingly perceive it as part of acceptable mainstream fashion, rather than a way to express their resistance to mainstream culture. It is important that despite the emphasis on sweetness and demureness, GothLoli does not endorse 'passive' femininity or objectification of women. As the Avant Gauche website indicates, GothLoli has no direct reference to Nabokov and his novel, and generally in relation to the fashion, it has no sexual connotations. ${ }^{27}$ This idea is credible because although those who dress in this fashion style often overemphasise demureness and sweetness, which conceivably appeal to some men, Japanese Lolitas also tend to endorse the egoism and cruelty associated with childhood rather than its innocence, naiveté or submissiveness. Thus, they do not seem to endorse passivity or vulnerability. Moreover, their emphasis on sweetness and cuteness, both in fashion and manners, does not, at least not intentionally, evoke vulnerability, availability, or willingness to fuel male fantasies as Merskin argues American 'Lolita' does. It should be noted that many Lolitas differentiate themselves from maid cosplay fashion where young women dress in similar, but distinctive styles from GothLoli (or French Maid). One possible reason is that the maid style which is strongly associated with maid cafés ${ }^{28}$, tends to operate for the objectifying gaze of men, particularly those who are considered to be otaku ${ }^{29}$, and often connotes emphasised (superficial) submissiveness (after all, they are dressed as maids).

The concept of 'Lolita' is essentially aesthetic as it is applied to the lacy, elaborate, and girlish doll-like sweetness of the fashion. This idea is reinforced by the interviews with GothLoli followers, who refer to its cuteness and sweetness, and its suitability for their taste, as the main reason for dressing in the style. ${ }^{30}$ Also, the magazine Gothic \& Lolita Bible provides a catalogue for clothing brands that distribute GothLoli-style clothing. This indicates its mass-marketed nature and its aim to encourage casual participation and enjoyment if it suits an individual.

\footnotetext{
6 Martin, Brough, \& Orrego, Get It On.

27 Avant Gauche, op. cit.

28 A Maid café is where young waitresses are dressed as and play the role of maids. The maids and their customers engage in a pseudo master-servant relationship with 'definitely no sexual overtones about the whole situation' [http://www.japaneselifestyle.com.au/Tokyo/maid_cafe.htm].

29 According to Orbaugh and Buckley (2002), the word otaku has connotations similar to 'nerd' in English though sometimes it is used to suggest unsociability, and even psychopathy. Outside Japan, the term is generally used to describe devoted fans of manga and anime. In recent times, the word akibakei (Akihabara-style) has increasingly been used to describe the (otaku) subcultures that emerged in the district of Akihabara, and the followers of these subcultures.

30 Gothic \& Lolita Bible, vol. 5, pp. 83-86.
} 
In order to understand GothLoli in the context of cultural globalisation, it is useful to refer to the theory articulated by scholar Okamura Keiko. ${ }^{31}$ According to her theory of 'format' and 'product', historical European fashion styles (the 'format') became transnational, and then 'localised' in Japanese culture. When the 'format' is then hybridised with the local aesthetic notion of cute, it engenders a fashion form peculiar to Japan. The 'product' of this transcultural flow reflects the emphasis on the fusion of elaborated sweetness and cuteness, a quality unknown in Western Goth subculture. However, this may support the commonly held notion of cultural globalisation as localisation and subsequent homogenisation of Western culture. This point is summarised in anthropologist Jonathan Friedman's claim in relation to similarities between cultural globalisation and European colonialism in the eighteenth century. Friedman contends that 'the things and symbols of Western culture have diffused into the daily lives of many of the world's people... yet still their mode of appropriating these things is vastly different from our own. ${ }^{32}$ In this idea, the differences between 'global' (our) and 'local' (their) cultures, and possibly their hierarchal relationships (i.e. global/ dominant, local/ subservient) are sustained even after 'global' cultural forms are localised.

What theorists like Friedman tend to disregard, however, is 'countercurrents the impact nonwestern cultures have been making on the West. ${ }^{33}$ Those who affirm the direct correlation between cultural globalisation and Westernisation do so by assuming the sole dominance of Western culture, and hence assuming the centrality of Western culture against peripheral non-Western cultures. This idea is challenged by Appadurai who argues that neither the centrality nor the peripherality of culture exist any longer. Moreover, the idea of the countercurrent or 'reverse' flow of culture indicates the potential of cultural forms to circulate in multiple directions. Consequently, this suggests the potential of various cultures to become active components of cultural globalisation. One of the ways to compare these impacts or 'reverse' flow of GothLoli on the West is via different aesthetical conceptions of 'cuteness' in the West and Japan. White argues that there is a tendency in the United States to encourage even small girls in elementary school to dress in mature, sexualised clothes. In Japan, in comparison, high school and college-aged girls, and even young women and men are allowed to associate with cute styles without much social objection. ${ }^{34}$ Merskin's concern over the American trend where women 'dress down' to achieve a baby-doll look also indicates that in the United States the concept of 'cuteness' should only be applied to small children. Moreover, Wilkins cites Sarah Thornton who argues that participants in youth culture denounce femininity as passive, undesirable, and unhip. ${ }^{35}$ In other words, American youth tend to reject

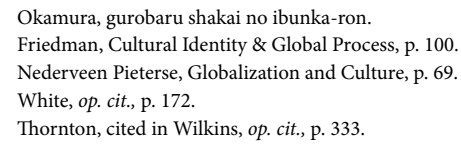


incus is

forms of femininity and demureness as undesirable. If these sentiments can be read as reflecting the West in general, it can be assumed that the association of youth/adult with cute and sweet styles may be generally considered inappropriate and unfavourable in the West. On the other hand, Kinsella claims that the Japanese cute style has directly and indirectly influenced Western youth culture since the 1990s, most notably in the 'Riot Grrl' style, where '[r]adical, assertive young women began to wear baby-doll dresses or old-fashioned frilly frocks, with Dr Martin [sic] boots and other macho accessories. ${ }^{36}$ According to her:

The tough but infantile Riot Grrrl style in Britain has been directly and indirectly influenced by Japanese cute culture, especially the sophisticated infantile styles developed around Tokyo's Cutie For Independent Girls magazine. ${ }^{37}$

Kinsella's point is further reinforced by the growing popularity of GothLoli outside Japan. For instance, BABY THE STARS SHINE BRIGHT, one of the most well known Lolita clothing brands, opened its first overseas store in Paris in 2007, indicating the fashion's potential to become accepted outside the context of Japanese culture and aesthetics. ${ }^{38}$ It is easy to denounce GothLoli as mere mimicry of Western fashion. However, its hybridised qualities in which European classic fashion styles interact with Japanese aesthetic concepts, and its subsequent countercurrents in the West, demonstrate that non-Western culture also influences Western culture. Social/ aesthetical differences between the West and Japan mean there are different interpretations of cuteness in those societies, which explains why this aesthetic concept was accepted without much resistance in Japan while it was, and still is, perceived in a rather negative light in many Western societies. In the next section I turn to GothLoli followers outside of Japan with particular attention to their perceptions of the fashion trend, and look at some of the issues in the context of cultural globalisation that surround it.

\section{Lives of 'Lolitas' Abroad: EGL The Gothic \& Lolita Fashion Community}

The existence of EGL ${ }^{39}$ The Gothic \& Lolita Fashion Community is a notable indication of the growing popularity and recognition of GothLoli worldwide. ${ }^{40}$ This English-speaking cyberspace community for GothLoli lovers provides a place where participants from more than 14 different countries ${ }^{41}$ exchange information, sell/ buy GothLoli items, discuss

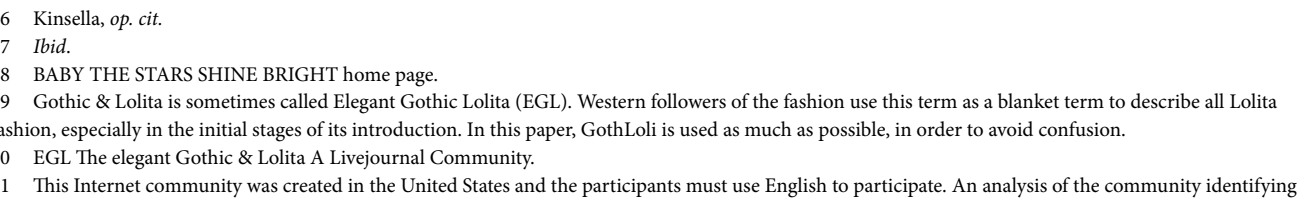


cultural/aesthetic issues, and interact with one another. I monitored and observed this community for seven months (from November 2004 to June 2005) in order to analyse the currency of the fashion trend outside of Japan. Participants ranged in age from twelve to thirty-five years old. It should be understood that this is the analysis of relatively active participants, and the community indeed has a much larger number of members who rarely participate or only visit and view the site. The author did not participate in the forum in any other form than as an informed observer, in order to neither disturb nor influence the flow of communication. ${ }^{42}$ Forum comments have been recorded and reproduced in this article as they were posted.

\section{GothLoli as an Independent Style}

Interestingly, the rules of the GothLoli Community in relation to auctions and direct sales state that ' $[i]$ tems must either be authentic Japanese brand Gothic \& Lolita clothing and accessories, well made replicas or items that follow the genuine style of Gothic \& Lolita. ${ }^{43}$ This is reinforced by a comment posted by the site administrator that, referring to the recent trend in which participants increasingly neither post for 'GothLoli' style nor the Japanese brands:

The reason that we allow sales posts in this community at all is to help people find things that they are not easily attainable outside of Japan and items that are rare. Western style gothic clothing and accessories are easily found by westerners, and there are other more appropriated forums for them.

Thus it is clear that the community treats GothLoli as a genuine and independent fashion trend rather than a mere mimicry of either Western Goth or Victorian dress fashion. It also clearly identifies and differentiates GothLoli from Western Goth style, which means members are aware of both Western Goth culture and GothLoli, and have made a decision to choose GothLoli based on their preference.

This point is reinforced further, when a common misconception that GothLoli is an 'illegitimate' offspring of Western Goth is mentioned. One Australian participant comments: 'just because it says Gothic in the name it doesn't mean that it's pertaining to Western Gothic subculture'. Another participant laments:

active participants' cultural origin reveals that 70 percent are from the USA, 5 percent from the UK, 5 percent from Canada. Other countries represented by a few individuals included Australia, Finland, Germany, Netherlands, New Zealand, Norway, Singapore, and South Korea.

42 The aim here is not to read this observation as reflecting general attitudes of GothLoli followers. Therefore, the author does not profess that the participants of the online community might be representatives of other individuals in their cultural environment, or of international GL followers. It is nevertheless worthwhile to examine how this particular fashion has been established within the lives of the participants. This is because, although this online community is a virtual place, it is likely to represent a partial part of the whole reality, where the actual Lolitas (GL followers) live.

43 EGL The elegant Gothic \& Lolita A Livejournal Community. 
.

Sadly EGL is already seen as "one of the bastard stepchildren of Goth" in many places... The problem is also sociological, people need to categorise things to get their head around them it seems, so EGL gets stuffed with Goth instead of with Japanese Street fashion in Europe mostly.

This common misconception contrasts with the way many participants see GothLoli. One participant comments it has an interesting look you hardly see in the Western Gothic Subculture'. Despite the common perception of GothLoli as an ('inferior') part of Western Goth culture in Western societies, the independent identity of GothLoli is assumed in this community as participants clearly distinguish it from the Western Goth subculture. Moreover, they have selected GothLoli not because they were forced to, but because it suits them for a variety of reasons. This illustrates the possibility that transnational culture and local culture can co-exist without homogenisation. Indeed, both identities of Western Goth and GothLoli are acknowledged by the participants, and GothLoli is appreciated by the participants precisely because of its qualities which are different from Western Goth.

\section{Gothic \& Lolita and Social Prejudice}

Although GothLoli suits the preference and aesthetic of the participants, prejudice about individuals dressing 'differently' from mainstream fashion is mentioned quite frequently in the community. For example, an Australian participant who currently lives in Japan, commenting on the entry of a young British male participant who declares his wish to dress in GothLoli style, notes:

Really, unless you can pass for a girl, wearing EGL in public might get you into trouble. In Japan there are guys who dress EGL and hang out in Harajuku, but I don't think the rest of the world would be too accepting. Maybe at clubs it would be okay, but otherwise I would be wary if I were you. Even girls who dress EGL in most countries get harassed.

In relation to skirts of metamorphose temps de fille, a famous Japanese Lolita brand known for its elaborate frills and 'Sweet Lolita' style ${ }^{44}$ an American participant comments: 'if it's super frill metamor, that's nearly impossible for even a cute girl to wear without being stared at. and, assuming you're not one, in a really frill dress you may be mistaken for an adult baby fetishist'. Other participants agree, supporting his wish to dress as he likes but warning him by revealing their experiences that all female Lolitas have a tough time going out dressed in GothLoli, and so for men it will be even harder. Similarly,

44 Metamorphose Temps de Fille, home page. 
one Finnish participant posts a comment asking for fellow Finnish participants. She notes that no one around her dresses in the style, and it is really difficult to dress in GothLoli alone in Finland, as 'over here it's really hars. it's enough to put on a skirt with a ribbon and you've got glares on you. But I'm doing my best.... Thus, prejudice related to teenagers and mature-aged individuals who dress in excessively cute and sweet fashion regardless of gender clearly exists in many countries. The discriminatory treatment of GothLoli and its followers in many societies also suggests that even though they adopt a fashion style which is relatively accepted in Japan, their lives are not likely to be standardised or 'Japanised'. This amplifies Appadurai's argument; in relation to the widespread popularity of Philippine renditions of American popular songs in the Philippines, he states:

But Americanization is certainly a pallid term to apply to such a situation, for not only are there more Filipinos singing perfect renditions of some American songs (often from the American past) than there are Americans doing so, there is, of course, the fact that the rest of their lives is not in complete synchrony with the referential world which first gave birth to these songs.

In other words, even if individuals adopt a transnational cultural form, this does not necessarily mean that their lives are completely infiltrated and standardised by the culture where the transnational cultural form originated. ${ }^{45}$ The experiences of harassment indicate that the participants are reminded constantly that such fashion styles are not favoured where they live. Thus, their lives are inseparable from their local cultures.

\section{Negative Conception of Gothic \& Lolita and the Western Concept of 'Lolita'}

Negative conceptions and treatments of GothLoli or individuals dressed in cute and elaborate, lacy clothes outside Japan and especially in Western societies seems to be, at least partly, due to the concept of American (Western) Lolita based on Nabokov's novel, and the deviant sexual connotations associated with it. One Canadian participant, for example, comments: 'Many people seem to think I look tarty or silly'. Another Canadian participant, in answer to the question of 'Is there anything you dislike about Lolita fashion?', notes: 'I guess the name. Lolita. Whenever people hear it they assume I'm some sort of whore. This idea is reinforced by another participant from the United States who expresses her anger at such assumption:

[I]t seems that most people's initial reaction to the style is to be squicked out by the idea of eroticizing pre-adolescence. The Lolita=Pedophilia thing bothers me by itself, but what

45 Appadurai, op. cit., pp. 271-2. 
.

really bothers me is the extent to which people cannot divorce the idea from how men perceive it...Is it really that impossible to imagine that women might occasionally spend alot of time on their appearance without it being for anyone else's benefit? I've had to answer time and again, "Why do you want to be infantilized/dis-empowered/victimized?" and the answer is of course, that I don't. I want to wear lace trimmed knee length skirts and puffy sleeves and hair ribbons. "shrug" It is fun and makes me feel pretty.

Many participants in the community indeed strongly deny the direct correlation between GothLoli and the concept of Western, sexualised 'Lolita' drawn from Nabokov's novel. One participant puts it: 'most girls who wear the style are exactly the opposite as Lolita from the book by Nabokov'. Such negative connotations associated with fashion styles like GothLoli in Western societies are explained by theorists like Merskins, who is alarmed by the increase in the eroticised 'Lolita' representation in the media, as such representation enforces sexualisation and exploitation of young girls. Such theorists' criticism of the concept assumes the direct correlation between the concept of 'Lolita' or grown people dressed in 'baby doll-style', and paedophilic fantasies and pornography. However, as I have shown, this is different in Japan where the fashion emerged. As White has noted, the concept of cuteness is not restricted only to children in Japan. ${ }^{46}$ This means that young people dressing cutely and sweetly are more accepted in Japan while in many Western cultures, it may be considered to be infantile or unnatural. Therefore, GothLoli is received and interpreted differently in Japan than in the West.

It is also noteworthy that some Western participants in these communities say that although teenagers and young people who follow 'mainstream' fashions tend to dislike GothLoli fashion, senior citizens and small children admire the fashion. This is indicated by some participants, including a Canadian who comments that ' $[\mathrm{m}]$ ost older adults, especially women, seem to like the way I dress'. Another participant says 'little girls LOVE it! 'Cause pretty much we're dressed like princess dolls to them'. These comments indicate that although GothLoli is generally perceived unfavourably in Western societies, the fashion trend is interpreted differently by individuals of different generations. Thus, Ulf Hedetoft's argument that different interpretations of culture may not only occur trans-nationally, but also between individuals who share the same culture/ nationality, is reinforced. ${ }^{47}$ This (re)interpretation of the transnational cultural flow may limit the capacity of the dominant ideology to overshadow the process and also illustrates the hollowness and instability of the dominant ideology - in this case, the Western concept of 'Lolita'.

\footnotetext{
White, op. cit., pp. 126-7.

7 Hedetoft, 'Contemporary Cinema: Between cultural globalization and national interpretation', p. 279.
} 


\section{Gothic \& Lolita and Individual Freedom in Western Societies}

Western societies' intolerance of people who dress 'differently' as indicated by the participants' unpleasant experiences problematises a common belief that Western societies value individualism while non-Western societies such as Japan value conformity over individualism. The idea of lack of freedom/individualism is often at the root of how the West describes Japan. For example, Phil Hammond, in his study of the representation of Japan in Western journalistic and scholarly accounts, mentions a report on human rights in Japanese prisons by BBC TV News which notes: 'They're regimented, but they are at least safe. Unlike many prisons in the West, violence among inmates is rare. In that sense Japan's prisons reflect society as a whole: fewer rights than in the West, but more security. ${ }^{38}$ According to Hammond, even the absence of any violence is used by Western media to emphasise how different, strange and exotic Japan is compared to the West. This tendency to exoticise is also prominent in the Western media's coverage of GothLoli. Such Western journalists as David Graham ${ }^{49}$, and Mark Schilling ${ }^{50}$ attribute GothLoli to a rebellion or reaction against Japanese society that imposes conformity. Graham, in fact, notes that 'Tokyo is a massive city dominated by a culture that demands conformity. "The nail that sticks up gets hammered down", was a common admonition toward children who dared to express their individual personality. ${ }^{51}$ It may be true that Japanese society demands conformity. However, participants in the online community I examined see it differently as far as fashion is concerned. One participant from the United Kingdom in fact argues that 'I would say Japan would probably be the only ACCEPTING place where you could run about and no-one blink twice. I've found the UK is probably the worst because we are a very reserved and set-in-our-ways country!. This argument is reinforced by a participant from the United States who says:

Dressing up should be for special occasions, like conventions, EGL EGA gatherings, Halloween, weekend trips to the shopping areas of your town with other friends dressed up, concerts, or clubbing and if you live in Japan of course... Why? Because society doesn't really understand individuality unfortunately and people might think you're living in a fantasy world, plus it's healthy to keep it on a "play dressup fantasy" level.

As these posts indicate, GothLoli followers tend to see Western societies as lacking the freedom of individualism as far as fashion is concerned while idealising Japan as a place where such freedom is preserved. Thus, common conceptions of Japan as a highly conformist society are called into question when we compare Japanese attitudes to this particular fashion with those in the West.

\footnotetext{
Hammond, 'The Mystification of Culture: Western Perception of Japan', p. 312

Graham, 'Gothic Lolita: Goth girls just want to have fun'.

Silling, 'Naughty and nice, sugar and spice'.

Graham, op. cit.
} 
.

\section{Gothic \& Lolita and 'Othering' Theory}

Whether or not GothLoli is the producer of a specific variant of a national (i.e. Japanese) fashion trend depends on the participants' interpretation of the fashion. As already argued, the online community generally treats Japanese GothLoli brand clothing as 'authentic', and the rules of the GothLoli online community state that GothLoli is a Japanese fashion trend, and differentiates it from Western Goth and other fashion styles that are considered 'Western'. Moreover, a majority of participants consider the fashion trend as Japanese, or at least Japan-oriented. In answer to the question of what 'Lolita' styles are included in the term 'GothLoli', one participant argues: '[i]t is the Gothic AND Lolita community, meaning it encompasses all of Japanese Gothic and Lolita fashion'. Some participants even express their own concern that GothLoli has rather 'inappropriately' been interpreted by Western individuals, as illustrated by an English participant's comment: 'westerners, instead of bringing loli straight from Japan, decided to modify it a bit, so now it looks tarty and sort of kinky, which i believe Lolita clothing is trying to avoid. The complex history of the fashion -the Rococo and Victorian inspired fashion style developed in Japan which has been re-exported to the West -however, seems to provide the background for different interpretations. Few participants in fact raise objections to the common perception of GothLoli as a Japanese fashion trend. For example, following the post by a Dutch participant who notes some Western participants' 'wrong' interpretations of the 'Lolita' aesthetic as what she dislikes about the fashion trend, one participant claims that: '[b]ut the Japanese stole the style original from Europe, so what?'. This comment is followed by one participant from Canada, saying: 'True.' Furthermore, another participant denies the Japanese origin of the fashion trend, saying: '[I]t isn't an original fashion or Japanese fashion at all'. Hedetoff ${ }^{52}$ has explained this process of globalisation as one where the 'receivers' (participants) engage with the fashion as either Japanese or European culture, depending on their pre-understanding of the fashion as Japan-oriented or European-influenced. The sender (the Japanese fashion trend) itself has emerged from the hybridisation of European fashion and a Japanese aesthetic, and thus, is likely to be multicultural. In this sense, it can be argued that for Western participants, GothLoli seems to represent difference from as well as affirmation of their own cultures.

Although different interpretations of the origin of the fashion trend are seen in the online community, only a few of them, if any, mention its exotic 'Japaneseness' as a main attraction. Thus, most Western participants do not seem to define their own identity by 'othering' Japan and GothLoli. Well known stereotypes associated with Japan and Japanese culture such as a paradoxical combination of traditionalism - samurai,

52 Hedetoft, op. cit., pp. 281-2. 
geisha (Italics theirs) etc. - and high-technology, which can be seen in Hollywood films such as Bladerunner or Black Rain ${ }^{\prime 53}$ are in fact not found in this community. Therefore, it may be argued that such Western participants who consider GothLoli as a Japanese fashion trend do not emphasise any cultural difference in order to define their own identity as 'Westerners'. Rather, those who regard the fashion style as having a foreign origin seem to be aware of their position as 'absorbers', actively accepting and participating in the fashion trend. So we can conclude that these participants appreciate the style not because it signifies cultural differences, exoticism or 'otherness', but because it simply suits their preference. In this sense, for them, what is important is the content, and suitability for their preference, certainly not where it came from.

\section{Gothic \& Lolita for Eternity?: Future Possibilities and Concluding Thoughts}

\section{GothLoli and Further Hybridisation}

Because of the expense, different physicality, and lack of availability of GothLoli clothes outside Japan, many participants purchase what are considered as 'GothLoli -esque' clothes from local (second hand) shops, or sew them themselves. As a result, some 'hybrid' Lolita fashions have emerged. From observing EGL The Gothic \& Lolita Fashion Community, further hybridisation and 'glocalisation' of GothLoli is predicted by some online discussion participants. For example, under the topic of the growing popularity of GothLoli in Finland, one participant claims that 'I'm 100 percent positive that lolita fashion as such, in it's authentic Japanese form, will never become a major trend in Finland, but rather, it will more or less influence the already existing styles'. Commenting on that, another participant notes 'Punkloli is very easy to implement in the pre-existing 'punk' trend, and teeniegoths have mainly adapted the more gothic (or generic bxw) version of Lolita into their wardrobes'. Yet another participant claims that so-called Punk Lolita (fusion of hard punk tops and frilly, lacy skirts) has gradually become closer to Japanese style due to the growing popularity of Japanese popular culture in contemporary Finland. These comments indicate that GothLoli is again in the process of change, as the likely hybridisation, localisation, interaction as well as appropriation is taking place once it is introduced to other cultures. Women's studies scholar Lauraine LeBlanc argues that 'girl punks' attempt to challenge and subvert passive femininity and its mandated beauty by deploying aggressive behaviour and punk style. ${ }^{54}$ From one point of view, GothLoli is the antithesis of 'girl punks' as the former is defined by its sweetness and cuteness while the latter is defined by aggressiveness and rebelliousness. However, from another point of view, emphasising sweetness, demureness and

Iwabuchi, 'Complicit exoticism: Japan and its other'.

54 LeBlanc, 1999, cited in Wilkins, op. cit., p. 333. 
.n.m.n. of

femininity without seeking the objectifying male gaze mirrors the aims of girl punks to reject the mainstream representation of femininity as passive, compliant, and powerless against the sexual objectification of women. This affinity between the two styles, and GothLoli's compatibility with punk style, reinforces Nederveen Pieterse's claim that cultural hybridisation expresses cultural affinities rather than 'exoticism. ${ }^{55}$

\section{Conclusion}

The emergent popularity of Gothic \& Lolita (GothLoli) tells us that non-Western cultures can and are being accepted and understood globally. This reinforces Appadurai's idea that there may not be a centre in this transcultural flow, as it is a complex and overlapping process that flows in multiple ways. Despite the fact that the style of GothLoli originated from historical Europe, the doll-like elaborateness, sweetness and elegance of the fashion was relatively easily developed in Japan where the concept of cuteness and sweetness is not restricted to children. The fashion's appreciation of demure mannerisms and sweetness without the restrictions of 'passive' femininity and aggressive masculinity have, in turn, attracted individuals in Western countries. The globalisation of GothLoli is therefore, not homogenising an already existing culture, in this case Western Goth, but is providing those who prefer something elaborate, sweet and demure as an alternative to their own fashion cultures.

As GothLoli is a clear fusion of Western and non-Western cultures, as a historical European dress style which is hybridised with a Japanese aesthetical concept of cute, it has formed a style that is neither European nor Japanese, but at the same time both European and Japanese. Furthermore, Japanese culture itself has always undergone cultural hybridisation: as Morris states, "[ $t$ ]he seventh and eighth centuries were one of Japan's great "borrowing" periods. ${ }^{56}$ Thus, what we call Japanese culture is the result of centuries of cultural hybridisation. This can certainly be said for almost any culture. Finally, as the participants in the online forum for GothLoli indicate, this fashion style is again in the process of change. Assuming that Nederveen Pieterse's theory that globalisation and cultural hybridisation have been taking place throughout world history, it is fair to declare that culture is in fact a process of eternal hybridisation, interaction and appropriation. 


\section{References}

Appadurai, A., 'Disjuncture and Difference in the Global Cultural Economy' in Robbins, B. (ed.), The Phantom Public Sphere (Minneapolis: University of Minnesota Press, 1993), pp. 269-95.

Avant Gauche website, http://www.avantgauche.co.uk/.

BABY THE STARS SHINE BRIGHT Home Page, http://www.babyssb.co.jp.

Bauman, Z., 'On Glocalization: Or Globalization for Some, Localization for Some Others', Thesis Eleven, no 54 (August 1998), pp. 37-49.

EGL The elegant Gothic \& Lolita A Livejournal Community, http://www.livejournal.com/community/egl/.

Friedman, J., Cultural Identity \& Global Process (London: Sage Publications, 1994), pp. 15-41, 91-101.

Get It On (Documentary) 2004, Canada, Chuma Television, produced by Marcia Martin, Brad Brough, and Pedro Orrego.

Gothic \& Lolita Bible (2002), vol. 5.

Graham, D., 'Gothic Lolita: Goth Girls just want to have fun', The Toronto Star, 23 July 2002, Retrieved from http://www. geocities.com/gothicunity/gothiclolitas.html.

Gunn, J., 'Marilyn Manson Is Not Goth: Memorial Struggle and the Rhetoric of Subcultural Identity' Journal of Communication Inquiry, vol. 23, no. 4, (1999), pp. 408-431.

Hammond, P., ‘The Mystification of Culture: Western Perception of Japan' Gazette, vol. 61, no. 3-4, (1999), pp. $311-325$.

Hannerz, U., 'The cultural role of world cities' in Cohen, A. \& Fukui, K. (eds.), Humanising the City? (Edinburgh: Edinburgh University Press, 1993), pp. 127-39.

Hedetoft, U., 'Contemporary Cinema: Between cultural globalisation and national interpretation' in Hjort, M. and Mackenzie, S. (eds.), Cinema and Nation (London: Routledge, 2000), pp. 278-297.

Hell, K., (2002) 'Elegant Gothic Lolita’ Morbidoutlook.com, Retrieved 6 March 2004, from http://www.morbidoutlook. com/fashion/articles/2002_07_gothiclolita.html.

Hodkinson, P., Goth: Identity, Style and Subculture (New York: Berg, 2002), pp. 35-64

Ishikawa, L., ‘Guide to Gothic \& Lolita Culture’ Gothic \& Lolita Bible, vol. 5, (2002), pp. 88-89.

Iwabuchi, K., 'Complicit exoticism: Japan and its other’ The Australian Journal of Media \& Culture vol. 8, no. 2 (1994).

Jameson, F., 'Notes on Globalization as a Philosophical Issue' in Jameson, F. and Miyoshi, M. (eds.), The Cultures of Globalization (Durham and London: Duke University Press, 1998), pp. 54-77.

Kinsella, S., 'Japanization of European Youth' Nightwave (1997) Retrieved 26 April 2002, from http://www.kinsellaresearch. com/Japanization.html.

Maid Café article on Japanese Lifestyle Home page, Retrieved 20 October 2008, from http://www.japaneselifestyle.com. 
New Voices Volume 2

au/Tokyo/maid_cafe.htm

Merskin, D., 'Reviving Lolita? A Media Literacy Examination of Sexual Portrayals of Girls in fashion Advertising' American Behavioural Scientist vol. 48, no. 1, (2004), pp. 119-129.

Metamorphose Temps de Fille Home Page, http://www.metamorphose.gr.jp/english/.

Morris, I., The World of the Shining Prince: Court Life in Ancient Japan (London: Penguin Books, 1979), pp. 11-24.

Nederveen Pieterse, J., Globalization and Culture: Global Mélange (Maryland: Roman \& Littlefield Publishers, 2004).

Okamura, K., Gurobaru shakai no ibunka-ron (Cross-cultural Theory in Global Societies) (Kyoto: Sekaishiso-sha, 2003), pp. 116-154.

Orbaugh, S. and Buckley, S. 'Otaku' in Buckley, S. (ed.), Encyclopedia of Contemporary Japanese Culture (London and New York: Routledge, 2002), pp. 379-80.

Robertson, R., 'Glocalization: Time-Space and Homogeneity-Heterogeneity' in Featherstone, M., Lash S. and Robertson, R. (eds.), Global Maternities (London: Sage Publications, 1995), pp. 25-44.

Ross, K. and Nightingale, V., Media and Audiences: New Perspectives (Berkshire: Open University Press, 2003), pp. 72-94.

Silling, M., 'Naughty and nice, sugar and spice', The Japan Times. Retrieved 23 June 2004, from http://search.japantimes. co.jp/cgi-bin/ff20040623a2.htm.

Shimotsuma Monogatari (motion picture) 2004, Japan, Toho, directed by Tetsuya Nakajima, starring Kyoko Fukada and Anna Tsuchiya, based on the novel by Novala Takemoto.

Stevens, C. S., Japanese Popular Music: Culture, authenticity, and power (London and New York: Routledge, 2008), pp. 56-8.

Suzuki, M., 'Gothic \& Lolita wa kansaikara umareta’ Yaso \# Goth (2003), pp. 118-9.

White, M., The Material Child: Coming of Age in Japan and America (New York: The Free Press, 1993), pp. 103-139, 169-195.

Wilkins, A. C., 'So Full of Myself as a Chick: Goth Women, Sexual Independence, and Gender Egalitarianism' Gender \& Society, vol. 18, no. 3, (2004), pp. 328-349.

Yomota, I., Kawaii Ron (Theory of Cuteness), (Tokyo: Chikuma Shobo, 2006). 